\title{
STRATEGIES FOR PREVENTION OF HYPERGLYCAEMIC EMERGENCIES IN NIGERIA
}

\author{
*Balogun WO and *Adeleye JO \\ *Department of Medicine, University College Hospital, Ibadan
}

\section{Correspondence}

Dr. Balogun W.O.

Consultant Endocrinologist

Department of Medicine

University College Hospital,

Ibadan, Nigeria.

E-mail: balogee@yahoo.com

\begin{abstract}
SUMMARY
The mortality and morbidity of acute metabolic complications of diabetes, particularly DKA and HHS are unacceptably high in Nigeria. Prevention of occurrence of these hyperglycaemic emergencies (HE) is the only rational way for a resource poor country like Nigeria. Prevention requires careful identification of precipitating factors of $\mathrm{HE}$. The leading precipitating factors of $\mathrm{HE}$ in Nigeria are infections, inadequate or inappropriate use of anti-diabetic agents, especially insulin. HE may also be the first presentation in persons previously unknown to have diabetes. Measures to prevent HE include creation of awareness in the public, effective and systematic education of the persons living with diabetes and capacity building and manpower development of the healthcare personnel. There should be critical appraisal of our healthcare system with a view to restructuring so it can be more accessible to patients and can deliver quality diabetes care. Finally government must sincerely provide an alternative of healthcare financing for the citizens, especially those living with chronic medical conditions like diabetes.
\end{abstract}

\section{INTRODUCTION}

Diabetes is frequently associated with acute metabolic complications. Acute complications occurring in diabetes can broadly be divided into metabolic and non-metabolic. The non-metabolic complications include severe infections such as sepsis, malignant externa otitis etc. The focus of this section however will be on the acute metabolic (hyperglycaemic) complications which include: Diabetic Ketoacidosis (DKA), Hyperglycaemic Hyperosmolar State (HHS) and lactic acidosis. Lactic acidosis rarely occurs now because phenformin, a type of biguanide and the commonest causative drug agent is no longer in use. However lactic acidosis can still occur in some clinical situations like shock, cardiac, hepatic or renal decompensation, especially in the patients receiving metformin (biguanide) for treatment of diabetes. We shall therefore restrict ourselves to DKA and HHS which together constitute hyperglycaemic emergencies (HE) for the purpose of this article.

DKA by definition consists of the occurrence of a triad: hyperglycaemia, ketonaemia and high anion gap metabolic acidosis ${ }^{1}$. HHS (old terms were "hyperglycaemic hyperosmolar non-ketotic state or coma) is similar but different from DKA in that ketonaemia is minimal, hyperglycaemia and osmolality are much higher and consequently, dehydration is more severe $^{1}$. The underlying pathophysiological problem is absolute (DKA) or relative (HHS) deficiency of insulin with increase in the concentration of counterregulatory hormones especially glucagon. Any unconscious patient who is dehydrated should have his/her blood glucose quickly checked. The clinical presentation of DKA and HHS are similar, though with few areas of major difference. The patient with DKA is usually young and lean while HHS is usually elderly. Both present with prostration, polyuria, polydipsia and often have alteration in level of consciousness. Major areas of differences are that clinical evolutions of symptoms tend to be relatively more rapid in DKA than HHS, usually over a period of 2-3 days. Patients with DKA may also present with nausea and vomiting, and occasionally abdominal pain. Kussmaul (fast and deep) breathing may occur in both types, but especially in DKA. Other physical findings include dehydration, tachycardia and hypotension

\section{Epidemiology}

The incidence of HE is increasing worldwide ${ }^{2}$. The annual incidence of DKA from population-based studies is estimated to range from 4 to 8 episodes per 1,000 patient admissions with diabetes ${ }^{2}$. There is rarity of data on the annual incidence of HE in Nigeria. Even then, HE are leading causes of death in Nigeria ${ }^{3}$. Although the mortality rate of these complications is reducing in Western developed countries ${ }^{4}$, the situation has not changed in developing countries like Nigeria. Okoro and co-workers in Ilorin reported a crude 
mortality rate of $22 \%$ and $25 \%$ for DKA and HHS respectively ${ }^{5}$. In a retrospective study in Ife involving 144 diabetic patients, DKA was the commonest cause of death out of 25 deaths recorded in the 6 years of study ${ }^{6}$. More recently, Ogbera and co-worker reported a crude mortality rate of $20 \%$ among 111 diabetic patients in Lagos ${ }^{7}$. A combination of factors are responsible for this high mortality, including a poor and inefficient health system- especially grossly poor laboratory support, shortage of well-trained qualified health personnel, ignorance about diabetes and its acute complications. Perhaps the biggest factor is financial constraints, seen in majority of the patients who, together with their relatives directly bear the cost of healthcare in Nigeria.

It is important that $\mathrm{HE}$ be prevented in Nigeria, not only because it is an important cause of premature death in patients with diabetes, but also because the average individual cannot afford the cost of treatment. In the United States of America where direct and indirect costs of management can be readily quantified, it has been reported that the average cost per patient per hospitalization is $\$ 13,000^{8}$. Moreover, at present the country cannot boast of a robust and efficient healthcare system not to talk of modern facilities in most places to effectively manage HE. This latter reason perhaps underpins the vexatious high mortality rate in Nigeria. Therefore the only rational way is prevention. Fortunately, HE can be prevented to a great extent. However strategies for prevention must be crystallized and rigorously instituted in order to stem the burden of mortality resulting from hyperglycaemic emergencies (HE).

\section{Precipitating factors}

Identification of precipitating factors is crucial to formulating an effective prevention strategy for $\mathrm{HE}$. The 2 commonest precipitating factors of HE globally, in order, are infections and inadequate or inappropriate insulin therapy ${ }^{9-10}$. Although this is also true in our environment, emerging data in Nigeria and Africa showed that problems with insulin therapy is fast becoming the number one reason for developing $\mathrm{HE}^{7}$, 11. This is not surprising because of the prevalent poverty and limited availability of insulin in some places. The usual reasons for omitting insulin among diabetic patients include financial handicap to procure drug regularly. In fact many patients resort to selfdirected reduction of insulin dosage and frequency of dosing in order to delay procuring another vial. Insulin is also omitted due to ill health and erroneous belief that drugs should not be taken when ill, use of alternate herbal remedies and cultural misperception about use of insulin. Quite often, patients present for the first time in $\mathrm{HE}$, without being previously diagnosed as having diabetes ${ }^{7,10}$. This mode of presentation is not only common in patients with type 1 diabetes presenting with DKA but is also frequently seen in type 2 patients presenting with HHS. Comorbid illnesses such as stroke, myocardial infarction, and pancreatitis may also precipitate the conditions. Drugs such as steroid, thiazide diuretics, propanolol, phenytoin and alcohol are notable precipitants. Sometimes physical or emotional stress may be the trigger, especially among young females. In about $1-2 \%$ the precipitating agent may not be identified ${ }^{1}$.

\section{Strategies for Prevention}

It has been shown that when carefully thought and locally adaptable strategies are instituted, mortality from $\mathrm{HE}$ can significantly be reduced as the case in South Africa ${ }^{12-13}$. In a South African community, strategies formulated and implemented were found to cause a $15 \%$ reduction in mortality of $\mathrm{HE} 5$ years later ${ }^{13}$. One interesting finding in this study is that education of both patients and doctors can significantly reduce mortality.

Education: At the core of preventive measures is patient's education and empowerment. Prevention of hyperglycaemic emergencies is basically about focusing on the usual precipitating factors and empowering the patient through education to know how to avoid the precipitating factors or institute early intervention to prevent progression to full-blown emergencies. Patients with diabetes must acquire basic knowledge and skills on how to intelligently cooperate with the healthcare team in order to prevent sinister acute and chronic complications of diabetes. There should be a regular creation of awareness among the general public about diabetes and its untoward complications. People, especially those at risk of developing diabetes should be encouraged to go for screening tests. Those who are already diabetic must be taught the value of Self Monitoring of Blood Glucose (SMBG), analysis of glycaemic records and implications of different glucose readings. Furthermore, they must be taught how to handle sick days; for example, not to stop their anti-diabetic drugs, eat foods that are easy to digest and drink sugar-free fluids when appetite is suppressed or lost. They must be counseled to promptly communicate with and/or contact their doctors. This is now made relatively feasible with the advent and widespread use of mobile phones by the average Nigerian, even those in the low socio-economic strata. An emergency line can be created in the hospital by the healthcare team through which patients can readily reach their care-givers. Capacity building through periodic training of the healthcare personnel especially doctors and nurses must be ensured in order to deliver optimum and effective care of patients with diabetes 
and thereby prevent development of acute complications or to abort a smoldering $\mathrm{HE}$ from progressing to full blown emergency. In this regard, a locally workable and adaptable protocol for management of $\mathrm{HE}$ is required and overdue.

Restructuring bealthcare system: Recommendation to institute effective diabetes education for patients and training of healthcare personnel draws attention to the fundamental need to critically appraise and restructure our healthcare system. This is because maximum and lasting benefits can only be reaped from measures advocated above if we have in place a robust and efficient healthcare structure. Okoro and his team in Ilorin, observed that about half of the 40 patients with $\mathrm{HE}$ in their cohort had attended the diabetic clinic at some point prior to hospitalization ${ }^{5}$. This signifies a failure of the health system in that place and is most probably true of the entire country. There are worthy examples in Africa, such as Ghana ${ }^{14}$ and South Africa ${ }^{15}$, where novel healthcare models for care of diabetic persons have been devised and implemented with significant positive impact on diabetes care. The present healthcare structure and system in Nigeria restrict accessibility to health facilities and will not support high quality care of persons living with diabetes. In a previous work, Adeleye et al advocated for measures to achieve a major increase in awareness and knowledge about diabetes, its complications and prevention amongst Nigerian health professionals especially at primary and secondary healthcare levels ${ }^{16}$.The introduction of Village Health Workers and establishment of diabetes centres were also suggested. All this calls for a radical restructuring of our healthcare delivery system.

Healthcare financing: Issue of compliance with medications at whatever level should receive compassionate counseling by the managing team. This is because in our environment at present, most patients are on the low socio-economic rung and worse still, are paying medical bills from their pockets with no effective insurance aid. The reality is that only a few percentage of the populace can self-finance their healthcare needs, especially a chronic, life-long health condition like diabetes. Government should speed up the process of ensuring effective health insurance scheme for the people. Availability and subsidy of antidiabetic drugs, especially insulin should be guaranteed by the government. Professional bodies like the endocrine associations as well as the Diabetes association in Nigeria must, backed by data of prevalence, incidence, mortality and morbidity of $\mathrm{HE}$, use every opportunity to draw the attention of government to the appalling situation of our healthcare system and infrastructures, particularly as it concerns diabetes care. It is this kind of intense and persistent advocacy that will cause government to realize that non-communicable diseases are taking an equally severe, if not more toll on the health of Nigerians like the communicable diseases.

Hyperglycaemic emergencies are preventable. Mortality and morbidity can and should be reduced by identification of the risk factors, effective education and empowerment of the diabetic patients, training of healthcare personnel and critical appraisal and restructuring of our health system with the government giving more than a passing attention to the plight of citizens living with diabetes.

\section{REFERENCES}

1. Kitabchi AE, Wall BM. Diabetic Ketoacidosis. Med Clin North Am;1995,79:9-37.

2. Johnson DD, Palumbo PJ, and Chu CP. Diabetic ketoacidosis in a community-based population. Mayo Clin Proc 1980; 55:83-88

3. Ogbera AO, Chineneye S, Onyekwere A, and Fasanmade O. Prognostic Indices of DM mortality. Ethn Dis. 2007;17:721-725.

4. Centers for Disease Control and Prevention. Diabetes Surveillance System. Atlanta GA: U.S. Department of Health and Human Services. 2003: Accessed at www.cdc.gov/diabetes/statistics/ index.htm

5. Okoro EO, Yusuf M, Salawu HO and Oyejola BA. Outcome of diabetic hyperglycaemic emergencies in a Nigerian cohort. Journal of Chinese Clinical Medicine.2007; 2(2):77-82.

6. Ndububa DA, and Erharbor GE. Diabetes mortalities in Ilesa, Nigeria: a retrospective study. Centr Afr J Med. 1994; 40(10): 291-292

7. Ogbera AO, Awobusuyi J, Unachukwu C, and Fasanmade O. Clinical features, predictive factors and outcome of hyperglycaemic emergencies in a developing country. BMC Endocr Disord. 2009; Mar 10;9:9.

8. Javor KA, Kotsanos JG, McDonald RC, et al. Diabetic ketoacidosis charges relative to medical charges of adult patients with type I diabetes. Diabetes Care. 1997; 20:349-354

9. Marshal SM, and Alberti KGGM. Diabetic ketoacidosis. Diabetes Ann. 1987; 3:498-526. 
10. Wachtel TJ, Silliman RA, and Lamberton P. Predisposing factors for the diabetic hyperosmolar state. Arch Intern Med 1987; 147:499-501.

11. Umpierrez GE, Kelly JP, Navarrete JE, Casals MM, and Kitabchi AE. Hyperglycemic crises in urban blacks. Arch Intern Med. 1997 Mar 24;157(6):669-75

12. Buch E, Irwig LM, Huddle KR, Krige LP, Krut LH, and Kuyl JM. Pointers to preventing hyperglycaemic emergencies in Soweto. S Afr Med J. 1983 Oct 22;64(18):705-709.

13. Huddle KR. Hyperglycemic emergencies in Soweto-five years on. S Afr Med J. 1986 Nov 8;70(10):637
14. Acheampong JW, Boateng KA, Eghan BA, Story P, Parry EHO and Thomlinson S. The impact of diabetes nurses in the Komfo Anokye Teaching Hospital, Ghana. Diabetes International 2000: 10; 81-83

15. Coleman R, Gill G and Wilkinson D. Noncommunicable disease management in a resourcepoor setting: a primary health care model from rural South Africa. Bull World Health Org 1998; 76: 633-640

16. Adeleye JO, Agada NO, Balogun WO, Adetunji OR and Onyegbutulem HO. Diabetes Care in Nigeria: Time for a paradigm shift. Afr. J. Med. Med. Sci. 2006; 35: 155-159 